\title{
Investigating the Impact of an Educational CAD Modeling Tool on Student Design Thinking
}

\section{Miss Manaz Rusi Taleyarkhan, Purdue University}

Manaz is a Master's student in Computer Information Technology at Purdue University who's research is focused on CAD simulations' effect on students' design thinking skills when tackling messy problems.

\section{Dr. Chandan Dasgupta, Purdue University}

Dr. Chandan Dasgupta received his Ph.D. in Learning Sciences from the University of Illinois at Chicago (UIC) where he was awarded the Chancellor's graduate research fellowship for his dissertation work on scaffolding students' productive disciplinary engagement with engineering design activities using suboptimal models. His research interests include the use of counterexamples as primary generators for supporting productive disciplinary engagement, integration of design thinking and scientific inquiry into K-12 education, and designing learning environments that help students generate and use design heuristics and make effective tradeoff decisions.

\section{John Alexander Mendoza-Garcia MSSEC, Purdue University, West Lafayette}

John Mendoza-Garcia is a Colombian Systems Engineer, and currently a Ph.D. candidate in Engineering Education at Purdue University. His advisors are Dr. Monica E. Cardella and Dr. William C. Oakes. In his dissertation, he is interested in understanding the development of the ability to deal with problems in Engineering complex socio-technical systems via variation theory. Other interests are curriculum development for mathematical thinking, design thinking, and human-centered design. He is currently on a leave of absence from the department of systems engineering at Pontificia Universidad Javeriana in Colombia. He worked as a software engineer in different companies for seven years before transitioning to academia.

\section{Dr. Alejandra J. Magana, Purdue University, West Lafayette}

Alejandra Magana is an Associate Professor in the Department of Computer and Information Technology and an affiliated faculty at the School of Engineering Education at Purdue University. She holds a B.E. in Information Systems, a M.S. in Technology, both from Tec de Monterrey; and a M.S. in Educational Technology and a Ph.D. in Engineering Education from Purdue University. Her research is focused on identifying how model-based cognition in STEM can be better supported by means of expert technological and computing tools such as cyber-physical systems, visualizations and modeling and simulation tools.

\section{Dr. Senay Purzer, Purdue University, West Lafayette}

enay Purzer is an Associate Professor in the School of Engineering Education. She is the recipient of a 2012 NSF CAREER award, which examines how engineering students approach innovation. She serves on the editorial boards of Science Education and the Journal of Pre-College Engineering Education (JPEER). She received a B.S.E with distinction in Engineering in 2009 and a B.S. degree in Physics Education in 1999. Her M.A. and Ph.D. degrees are in Science Education from Arizona State University earned in 2002 and 2008, respectively. 


\title{
INVESTIGATING THE IMPACT OF AN EDUCATIONAL CAD MODELING TOOL ON STUDENT DESIGN THINKING
}

\begin{abstract}
In this work-in-progress paper we present preliminary results of a study on the use of computeraided design (CAD) software to develop informed designers at the first year undergraduate level. There is a need for first-year undergraduate engineering students to engage productively with engineering design practices while using a CAD software in a group setting in a classroom environment. Existing research has classified students as mostly beginning designers or informed designers. The data collected are reflections written by 10 students in an introductory design course, one reflection after working individually in a design of an energy efficient house and another after working as part of a team on the same problem. The data were analyzed using as conceptual framework the informed design teaching and learning matrix developed by Crismond and Adams. Findings suggest the presence of a continuum consisting of four levels and highlight the shift in students' design practices towards higher expertise levels after using the CAD software in a group setting. While these are preliminary findings, they highlight the potential value of engaging first year engineering students with a CAD software in a group setting within formal classroom environment.
\end{abstract}

\section{Introduction}

Design has become an integral part of how engineering colleges prepare their students for professional practice. Prior work suggests that it is important to help students become "informed designers." This is the designer's mindset with a level of design expertise that falls between a novice designer and an expert designer (p.779) ${ }^{1}$. Strategies for facilitating this process have been previously reported in the literature with undergraduate students (e.g., Alien Centered design projects $^{2}$ ), and with high school students ${ }^{3}$ (e.g., with design challenges, or using a computeraided design (CAD) software developed by the Concord Consortium).

While prior research suggests that first-year engineering students need to experience learnercentered, contextualized, fully interactive, multimedia learning environments ${ }^{9}$, very little is known about the informed design process undertaken by these students while using the interactive and learning focused CAD tool to solve design challenge. Thus, this research aims to integrate an easy-to-use CAD software in the freshman engineering class and inculcate a habit of using CAD software as thinking tools as well as resources for making design decisions in an informed way. The scope of this research will include understanding the design strategies that first year engineering students develop and their level of expertise with these strategies while using a particular CAD software as a resource for solving an engineering design challenge. Specifically, this study is guided by the following research question: How do first year engineering students change their design practices after engaging with a design task using a CAD software in a group setting? 


\section{CAD Software Learning}

While the use of CAD software has been particularly favored for facilitating improvement in design process, we know very little about first year undergraduate engineering students' design behavior when they collaborate in teams and make decisions about design optimization using such CAD tools. The use of CAD software by designers and manufacturers goes back to the 1970s. CAD brought a revolutionary shift in the engineering industry and brought the designers and engineers closer together, generating a need for a workforce skilled in both engineering and designing practices. While the demand for such a skilled workforce remains high, there remains a dearth of such people in the industry. One of the primary reasons is due to the complexity of such CAD software and the steep learning curve that discourages many engineers from adopting CAD software in their daily processes. Also, CAD models are often viewed as finished products that have to be presented as opposed to a learning and design tool that can be changed and tested ${ }^{4}$. These issues offset the benefits of using CAD software, particularly the advantage of being able to simulate, test, and design ideas quickly and in a cost effective manner. Thus, there is a need to address this challenge early on in the engineering college level and help prepare a workforce of engineers that is comfortable working with CAD software and uses them as thinking tools while solving engineering challenges.

It is imperative that college students have experience with using CAD tools for solving authentic design challenges and develop design thinking. Such tools can scaffold the design thinking process and help them accomplish a task that is beyond their current abilities ${ }^{5}$. A survey of CAD designers revealed that CAD tools support creative problem solving process by supporting "enhanced visualization and communication, circumscribed thinking, premature design fixation and bounded ideation" (p.136 ) ${ }^{6}$. However, the focus on developing such skills and the use of such tools in the classroom context is not widespread and often overlooked by educators ${ }^{7}$. Moreover, evidence of effective teaching and learning techniques promoting design thinking and problem solving using such CAD tools has been scarce ${ }^{8}$.

\section{Collaborative Learning}

The idea of collaborative learning "involves individuals as group members, but also involves phenomena like the negotiation and sharing of meaning that are accomplished interactively in group process" ${ }^{\prime 10}$. Research on collaborative learning in Engineering Education has associated students' use of collaborative learning strategies with student's self-efficacy for learning course material and course grade ${ }^{11}$, and have also shown higher academic performance of students in a cooperative learning condition, than those who work individually ${ }^{12}$. Collaborative learning has been also linked to "active learning, student-centered learning, problem-based learning, and project-based learning"13, relevant methods commonly used in Engineering Education. Thus, investigating the effects on student learning of the design informed practices, after performing a collaborative design task mediated by an easy-to-use CAD software in the freshman engineering class will contribute to the body of knowledge that studies the interplay between technology and learning in the context of design. 


\section{Informed Design Framework}

As explained by Crismond and Adams, the process of informed design is a stage in the development of design thinking expertise that lies between the stage of a novice designer and an expert designer. The authors further go on to discuss how informed design teaching techniques engage the students in a way that enhances their own related skills and knowledge before coming up with new designs to solve the specifications of the problem's context. The learners can build upon their prior knowledge in order to reach a new solution, as opposed to a novice designer in which a solution is reached through trial and error. Trial and error problem solving does not guarantee conceptual closure ${ }^{1}$. The informed design approach requires a preexisting knowledge of the related math and science concepts that relate to the context of the design problem. This prior knowledge improves design performance and prompts inquiry learning ${ }^{1}$.

Crismond and Adams propose the Informed Design Teaching and Learning Matrix as a comparison between novice and informed designers ${ }^{1}$. We adopt the [matrix] as a framework to identify patterns in the student artifacts that can help us determine if informed design is being displayed. The Crismond and Adams framework identifies nine design strategies that designers both beginners and informed - typically engage with and specify behaviors that are indicative of both novice and informed designers. These are (a) understand the design challenge (problem solving vs. problem framing), (b) build knowledge (skipping vs. doing research), (c) generate ideas (idea scarcity vs. idea fluency), (d) represent ideas (surface vs. deep drawing \& modeling), (e) weigh options and make decisions (ignore vs. balance benefits and tradeoffs), (f) conduct experiments (confounded vs. valid tests and experiments), (g) troubleshoot (unfocused vs. diagnostic troubleshooting), (h) revise/iterate (haphazard or linear vs. managed and iterative designing), and (i) reflect on process (tacit vs. reflective design thinking) ${ }^{1}$. The Informed Design Teaching and Learning Matrix will help us characterize students' design practices and expertise level in the context of the teamwork using the CAD software ${ }^{1}$.

\section{Method}

We used a simple CAD software (ref. anonymized) that allowed students to design an energy efficient house iteratively. Students used this tool to digitally construct a house and simulate energy usage while working within a given set of constraints. The context of this study was a first year engineering design course in the first semester at a large Midwestern university. We assume every student had basic understanding of math concepts, computers, and energy. We also assume they were also sufficiently familiar with solving open-ended design problems that relate to real world engineering problems. The design challenge asked students to design a home based upon constraints such as cost, types of materials, dimensions, and position of the home relative to the sun. The problem specified a successful design as one that met the following criteria: (1) The total amount of energy that the building uses annually should be equal to or less than the total amount of renewable energy that it generates, (2) minimize total cost of the building (material cost), (3) should be easy to construct, (4) should have an attractive exterior or "curb appeal", and (5) comfortably fit a 4-person family. Students were required to record their design rationale in the form of reflections, first after working individually on their designs on the first day, and later, after creating a final solution as small teams. It is important to note that Reflection \#1 was done after students worked individually on the tool, and Reflection \#2 was done after the students 
worked with the tool as a team and completed the supplemental activities in the learning module. The learning module for the course was as follows:

\begin{tabular}{|l|l|l|}
\hline Class & Topics \& Tasks & Deliverables \\
\hline Day 1 & Learn to use software; Create an individual solution & Individual sol.; Reflection \#1 \\
\hline Day 2-3 & $\begin{array}{l}\text { Connect to the design cycle and evaluate designs; } \\
\text { Work as a team to create a team solution }\end{array}$ & \\
\hline Day 4 & Finalize team solution; Present solution to class & Team Solution; Reflection \#2 \\
\hline
\end{tabular}

The sample size of the entire dataset consists of 140 students. The data analysis in this paper is a subset and focuses on artifacts from 10 randomly selected students. These students were randomly selected from the bigger dataset. Students started by learning how to use the software and explore the affordances of the software individually. They then applied the material taught in lecture regarding design cycles and weighted decision making towards their interaction with the CAD tool in small groups for solving the design challenge. They applied any new knowledge towards improving their designs and then presented their design in front of their peers during a class presentation. All students filled out instructor-prepared reflection questions that probed them to understand their thinking process. Reflection assignment was given to the students before and after group work with the software. This assignment consisted of the following questions - (a) Describe a specific task you worked on as part of the Individual Solution.

(b) Describe a decision you made while working on the task. (c) Did your decision involve any trade-offs (compromises) or assumptions? (d) What resources or evidence did you use? (e) What would you do differently if you could do the task over? How could you improve your work? These questions in the reflection assignment were used for data-analysis.

We compared reflection \#1 and \#2 and used an adapted version of Crismond and Adam's framework to analyze these two sets of reflections. This framework was developed by using Crismond and Adam's framework for top-down analysis of the data and simultaneously conducting bottom-up analysis using content analysis approach. A top-down analysis of the data essentially decomposes the original framework to identify commonalities that could lead to breaking the categories down into more specific subsets. A bottom-up analysis pieces together data to give rise to a more complex framework that includes subcategories into the original Crismond and Adams framework. Based on our content analysis, two new expertise levels have been added to the existing framework, the adapted version that is shown in Table 1. The example quotes are taken from datasets that include reflection 1 and from reflection 2 in this study.

Table 1. Adapted and Summarized Informed Design Teaching and Learning Matrix ${ }^{1}$

\section{Understand the Challenge}

Beginner: Prematurely attempt to solve without identifying key components in problem structure. Example: "I worked on finding a way to lower the energy usage my model house was using for heating during the winter."

Adept Beginner: Consider at least one critical criteria or possibility of ambiguity in the problem, but make no active attempt to identify and document critical criteria. Example: 


\begin{abstract}
"Since the activity is individual, I was involved from the beginning till the end in which I had to design a house, decide on different materials, adjust the size and height based on instruction given, put solar panels and sensor and make sure that the building consumes no net energy over a year. "

Informed: Identified most critical criteria and constraints as well as the ultimate goal of the design task. Example: "We first gathered all the individual 3D models and revised each other's to get the best model possible, saving the most energy and create the most efficient model. Our best model of three models we got was the most simple in a rectangular shape of walls, net energy being below -800."
\end{abstract}

Adept Informed: Identify and describe many possible criteria and constraints and relate them to the ultimate goal of the design task.

Example: "I designed a house that was particularly appealing and comfortable, a design to be later combines with other ideas to get the final solution."

\title{
Build Knowledge
}

Beginner: Skip all research and begin solving.

Example: "I didn't really use any outside sources when building this solution, excluding the information I learned when completing the Pre-Quiz for this activity. I simply worked with the program enough so that I would know how certain changes would affect the energy efficiency of the home."

Adept Beginner: Conduct minimal research or investigate one design parameter before continuing the problem solving process.

Example: "I read the (anonymized) user manual and they commented about the uses of trees in the program, so I applied it to my house 's situation as well."

Informed: Do multiple investigations and research to learn about the problem, how the system works, relevant cases, and prior solutions.

Example: "I used several tests in differing configurations of the energy generated by the solar panels, as well as the energy usage with the house at different angles."

Adept Informed: Identify and describe many pieces of information in detail and relate them to the ultimate goals in the design task.

Example: "I gathered most of the information from the internet to increase my understanding in zero net energy buildings. I learnt a lot about differents material and the impacts they give and I found several suitable zero net energy building that I could refer to such as Zero-energy test building in Talinn, Estonia..."

\section{Weigh Options and Make Decisions}

Beginner: Criteria and constraints are not considered for decision making.

Example: "I decided to have two "must have" criteria because I felt this family needed both. They specifically were asking for a zero-efficiency house, but comfort is a given necessity and if they did not feel comfortable in their home, why would they live there. There were no tradeoffs as we could rank the criteria how we pleased and we could have had all of them be must haves or none. "

Adept Beginner: Criteria and constraints are acknowledged, but benefits and tradeoffs are not discussed. No examples found in this data set.

Informed: Use the trade-offs and potential benefits as the main input parameters of the decision making process. 
Example: "Increasing U-factor on all surfaces to keep the house cool, decreasing AC energy use. $N o^{\prime \prime}$

Adept Informed: In depth trade off analysis is displayed along with a clear understanding of the drawbacks and benefits of decisions. Clearly recognizing that the refined design is still not a perfect design.

Example :) "After I ran my initial energy analysis, I found out that my house model was inefficient since a large amount of heat was escaping through the windows in the house. I decided to change the window style from single-pane to triple-pane to lower the U factor of the windows. I assumed that if I used triple-pane windows with a lower U factor, the windows would be more insulated and more resistant to heat loss. "

\section{Reflect on Process}

Beginner: Conduct little or no reflection and monitoring activities to their plans or proposed solutions.

No example found in this dataset.

Adept Beginner: Conduct little reflection but do not take into account previous experiences or new information obtained.

Example: "I could make the house more appealing, while keeping its zero energy usage."

Informed: Conduct informed reflections based on previous experiences and iterations. Example: "If I were to do this activity again, and I had more time to complete the activity, I would try to make a different house for different climate zones and compare the maximum efficiency that I could achieve in each climate zone. In addition, if I were to do this particular task over again, I would try to increase the simplicity of the house without losing energy efficiency by using the same materials for all of the walls of the house."

Adept Informed: Recognizes that current design can be optimal but still imperfect, and therefore room for improvement. Actively and extensively conduct critical thinking practices and directly apply those results towards optimizing their design upon the next iteration. Example: "If I could the task over, I would definitely take some more time doing my reading and research on zero energy buildings first, before starting my design. This is because there are a lot more resources and information that need to be taken into account in building the house. Apart from that, I would definitely design a better-looking house that cost lesser than what I have designed now. The house would of course be a zero energy building and is ecofriendly one."

\section{Results and Discussion}

We found that students engaged with four of the nine design strategies- understand the design challenge, build knowledge, weigh tradeoffs and benefits, and reflect on the design. Figure 1 shows that the 10 students used similar design strategies before and after group work using the CAD software. However, from the distribution of different types of expertise evidenced by the students within these four design strategies, then we begin to notice the shift that happened between reflection \#1 and reflection \#2. In reflection \#1, there were 2 Beginning designers in 'Understand the design challenge' strategy and 7 Adept Beginning designers in this strategy. However, in reflection \#2, we see that most of the students (7) were Informed designers with a few (3) Adept Informed designers as well. We thus see a shift from Beginning and Adept Beginning designers towards Informed and Adept Informed designers. Students gained expertise at understanding the design challenge after working in groups on the design challenge and 
engaged with problem framing while paying attention to the design constraints and design goal. Figures 2 and 3 summarize the distribution of expertise level across different design strategies before and after team work using the CAD software respectively.

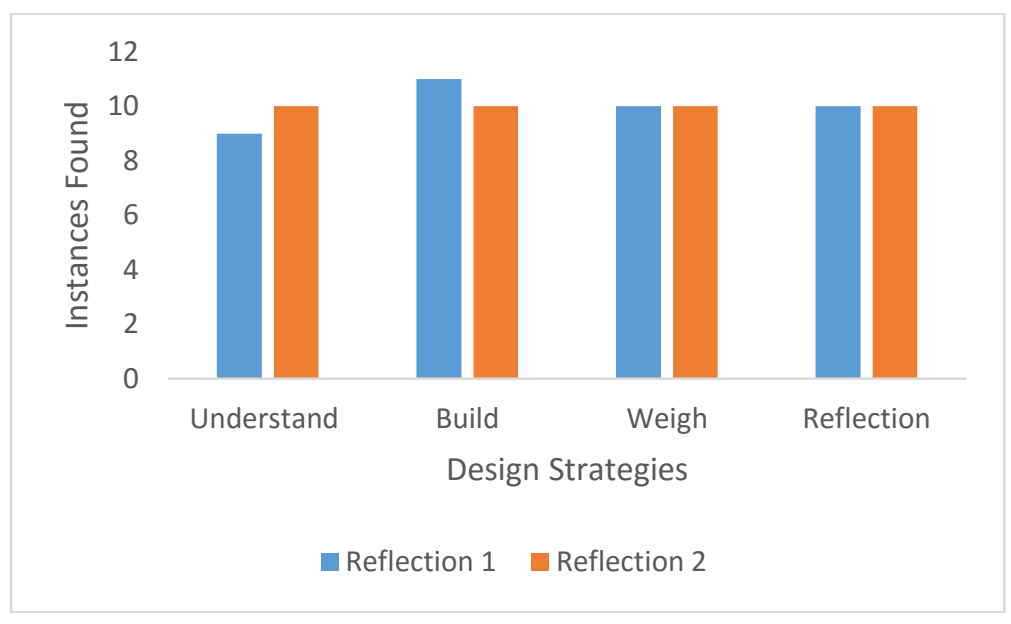

Figure 1. Counts of Design Strategies

It is likely that the CAD tool helped students understand the various variables and their relationship to each other by allowing students to isolate these variables during iterative design. The tool also may have allowed students to quickly adapt and revise features of the design based upon simulation results or new information gained. This procedure would be much more time consuming if students worked with physical prototyping materials at this stage instead of a CAD model. The easy-to-use visual feedback (e.g., graphs and heat map) given by the tool may have helped students frame the problem better instead of jumping into problem-solving mode like Beginning designers typically do.

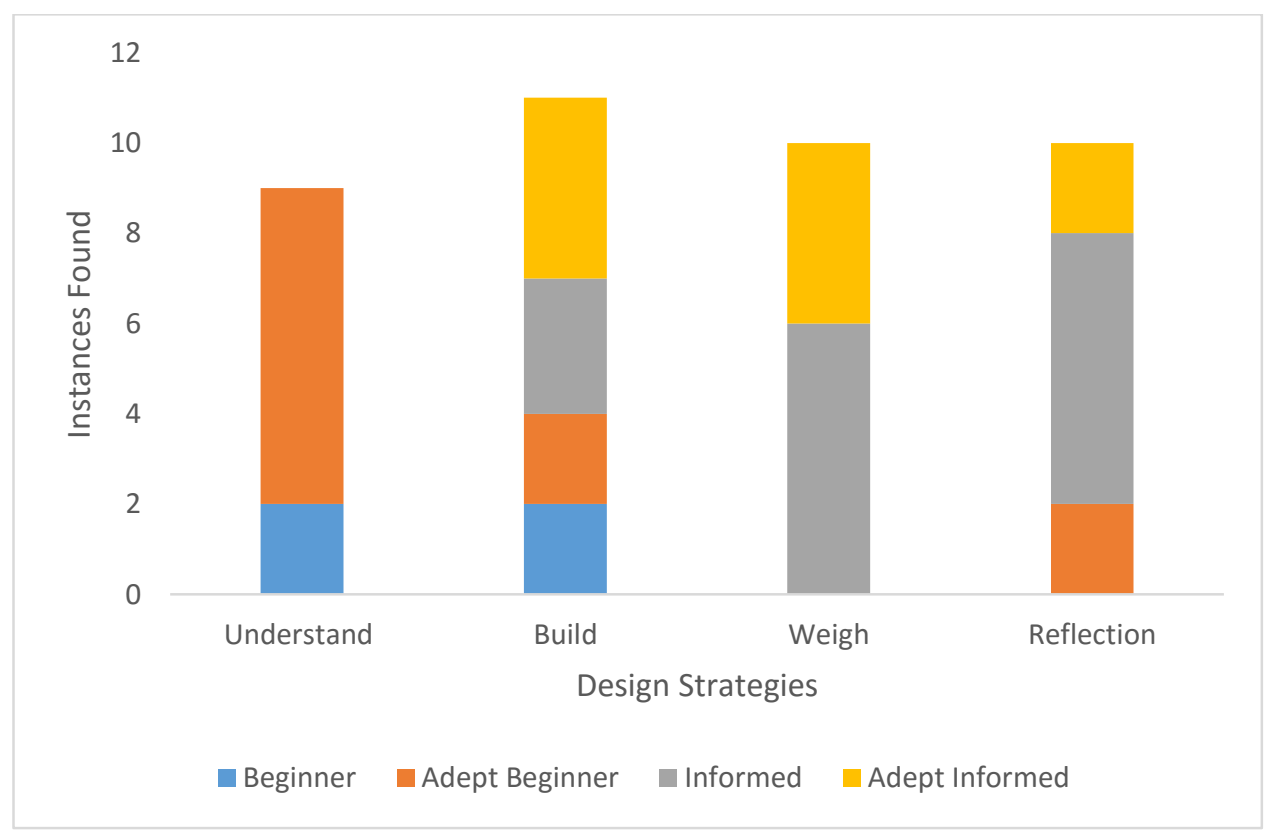


Figure 2. Distribution of expertise level across different design strategies before team work using CAD software

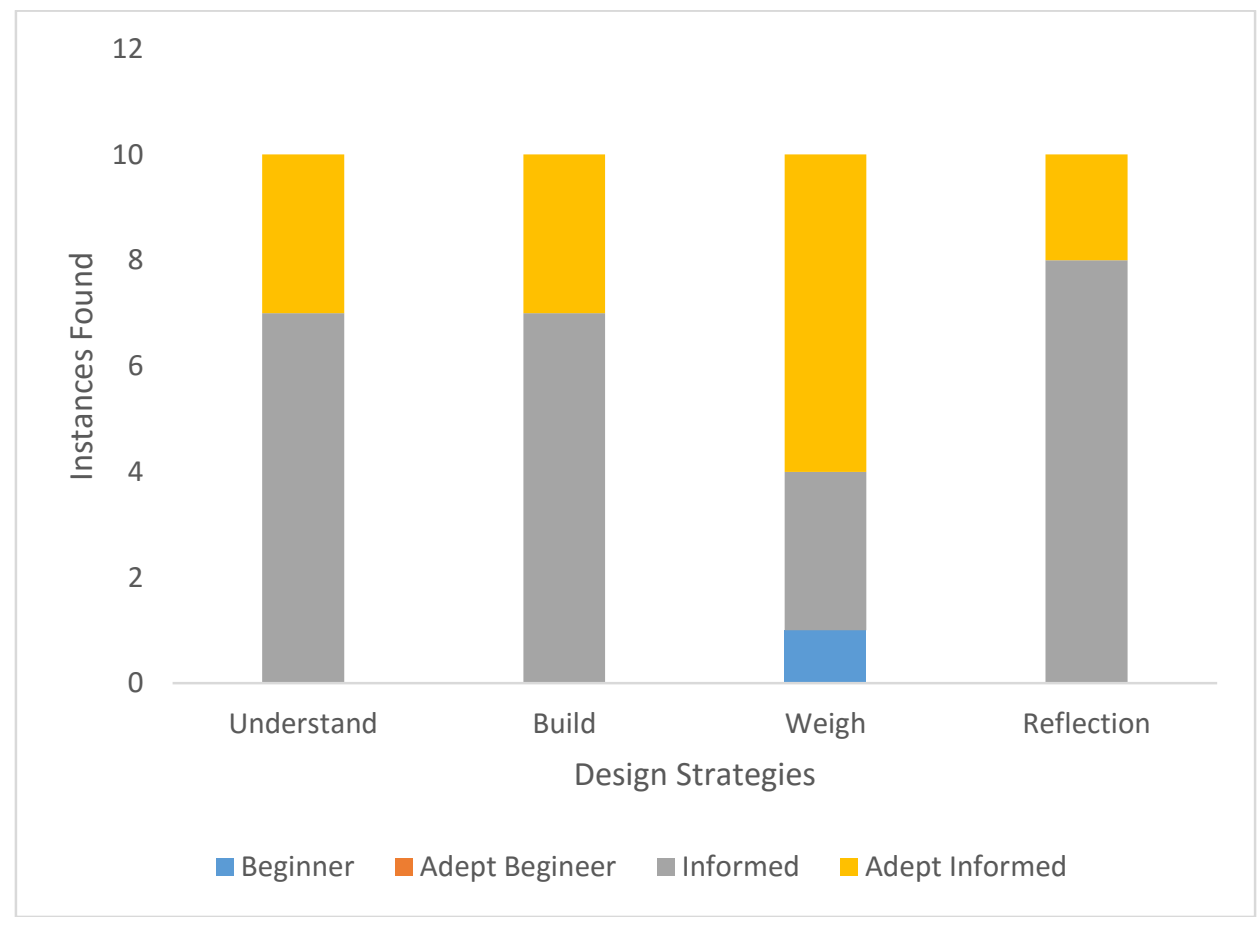

Figure 3. Distribution of expertise level across different design strategies after working in teams using CAD software

With regard to the "Build knowledge" design strategy, we found evidence that in reflection \#1 students displayed expertise levels across the entire spectrum- Beginning to Adept Informed. In reflection \#2, we found the majority of students (7 of 10) to be acting as Informed designers and the remainder ( 3 of 10) in the Adept Informed designer category. This is a shift where students made progress from being beginners towards being informed designers. One possible explanation for such a shift could be that the software provided easy to use reference materials (e.g., tutorials) that students could access any time during the design process. Additionally, the tool allowed students to explore the design space freely by clearly laying out all the available design parameters. This coupled with peer-feedback during the teamwork likely lowered the standards for the students to perform research and build knowledge about the potential solutions. Students exchange ideas regarding what information would be needed for solving the challenge based on their research.

For the "Weighing Options \& Decision Making" design strategy, there was an increase in the number of Adept Informed designers in reflection \#2 as compared to reflection \#1. In reflection \#1, there were 6 Informed and 4 Adept Informed designers. In reflection \#2, there were 6 Adept Informed designers and 3 Informed designers. The results from reflection \#2 are likely because the software scaffolded students' goal of making their models energy efficient by making different iterations available for easy review. Students could save their design iterations and review them as needed. Students could compare different iterations and the feedback from the 
tool likely helped determine which design decisions led towards the design of an energy efficient house. These features coupled with group discussions and peer-critique likely helped the students make informed and effective tradeoff decisions.

Finally, in the "Reflect on Progress" there was a distribution of Adept Beginner (2), Informed (6), and Adept Informed (2) in the initial reflection. In reflection \#2, the responses shifted to only Informed (8) and Adept Informed (2). This shift from beginner to informed could be because of the nature of the assignment; it explicitly asked students to reflect on their designs. However, during the reflection, the feedback from the software (e.g., cost distribution, energy consumption for a day and across a year) highlighted the drawbacks of their existing design. This may have helped students to consider their prior design experiences and critically think about their design with a view to optimize it in the next iteration.

\section{Conclusion}

This preliminary analysis suggests that there may be a continuum of levels of expertise as related to informed design. Results also suggest that teamwork using the CAD tool helped individual students make progress from beginner designers towards Adept Informed designers across all four design strategies- understanding the challenge, build knowledge, weigh tradeoffs, and reflect/revise. The CAD software scaffolded this process and students successfully used this software as a thinking tool to engage productively with the engineering practices. The ability to quickly iterate on designs after testing can help students develop traits that lead to becoming better designers. We acknowledge that further analysis of student designs and student work during the design process in small groups is needed to conclusively make stronger claims. Future work will include observing a larger number of student designs as well as possibly observing student group activity throughout the design process. However, this initial analysis highlights the potential benefits of such a learning environment using the CAD tool in promoting informed design practices at the first year engineering education level.

\section{Acknowledgements}

This research was supported in part by the U.S. National Science Foundation under the awards DUE \#1348547 and DRL \#1503436.

\section{References}

1. David P Crismond, Robin S Adams. The informed design teaching and learning matrix. Journal of Engineering Education. 2012; 101(4):738. http://search.proquest.com/docview/1635438387.

2. Mendoza-Garcia, J., \& Cardella, M. E. (2014, October). Using alien-centered design for teaching iteration in the design process in undergraduate design courses. In Frontiers in Education Conference (FIE), 2014 IEEE (pp. 1-8). IEEE.

3. Concord Consortium. (2010). Engineering Energy Efficiency.

4. Welch, M., Barlex, D., \& Lim, H. S. (2000). Sketching: Friend or foe to the novice designer? International Journal of Technology and Design Education, 10(2), 125-148.

5. Kern, C., \& Crippen, K. (2013, October). A Design Framework and Research Program for Enacting Science Cyberlearning. In World Conference on E-Learning in Corporate, Government, Healthcare, and 
Higher Education (Vol. 2013, No. 1, pp. 1195-1199).

6. Robertson, B. F., \& Radcliffe, D. F. (2009). Impact of CAD tools on creative problem solving in engineering design. Computer-Aided Design, 41(3), 136-146.

7. Weintrop, D., Beheshti, E., Horn, M., Orton, K., Jona, K., Trouille, L., \& Wilensky, U. (2014) Defining Computational Thinking for Science, Technology, Engineering, and Math. American Educational Research Association.

8. Kim, M. C., \& Hannafin, M. J. (2011). Scaffolding problem solving in technology-enhanced learning environments (TELEs): Bridging research and theory with practice. Computers \& Education, 56(2), 403417

9. Rhoads, T. R., \& Hubele, N. F. (2000). Student attitudes toward statistics before and after a computerintegrated introductory statistics course. Education, IEEE Transactions on, 43(2), 182-187.

10. Bratitsis T, Demetriadis S. Research approaches in computer-supported collaborative learning. International Journal of e-Collaboration. 2013;9(1):1. doi: 10.4018/jec.2013010101.

11. Stump GS, Hilpert JC, Husman J, Chung W, and Kim W. Collaborative learning in engineering students: Gender and achievement. Journal of Engineering Education. 2011; 100(3):475-497. http://onlinelibrary.wiley.com/doi/10.1002/j.2168-9830.2011.tb00023.x/abstract. Accessed January 28, 2016. doi: 10.1002/j.2168-9830.2011.tb00023.x.

12. Hsiung C. The effectiveness of cooperative learning. Journal of Engineering Education. 2012;101(1):119137. http://onlinelibrary.wiley.com/doi/10.1002/j.2168-9830.2012.tb00044.x/abstract. Accessed January 28, 2016. doi: 10.1002/j.2168-9830.2012.tb00044.x.

13. Göl Ö, Nafalski A. Collaborative learning in engineering education. Global Journal of Engineering Education. 2007;11(2):173-180. http://www.wiete.com.au/journals/GJEE/Publish/Vol.11,No.2/GolNafalski.pdf. 